J. Electroanal. Chem., 318 (1991) 349-367

Elsevier Sequoia S.A., Lausanne

JEC 01759

\title{
Electrochemistry of adsorbed flavin adenine dinucleotide in acidic solutions
}

\author{
M.M. Kamal ${ }^{1}$, H. Elzanowska, M. Gaur, D. Kim and V.I. Birss * \\ Chemistry Department, University of Calgary, Calgary, Alta. T2N 1N4 (Canada) \\ (Received 1 May 1991; in revised form 5 July 1991)
}

Abstract

The adsorption of flavin adenine dinucleotide (FAD) at a mercury electrode surface has been investigated in dilute FAD solutions from $\mathrm{pH}$ ca. 2-7. FAD is found to adsorb initially in an orientation in which the isoalloxazine and adenine moieties lie parallel to the electrode surface (Stage I) at all acidic $\mathrm{pH}$ values and potentials. At low coverage in Stage I, a persistent separation of the anodic and cathodic peaks is present, independent of sweep rate, perhaps indicative of the expected planar (oxidized) and nonplanar (reduced) conformations of the isoalloxazine ring system. As the surface coverage increases, this difference diminishes and a sudden reorientation occurs to a structure in which it is suggested that alternating isoalloxazine and adenine moieties are adsorbed perpendicularly to the electrode surface (Stage II). At $\mathrm{pH} \leqq 4.5$ this structure is stable over a very wide potential range. Also, a second vertical highly condensed orientation is observed at positive potentials in these more acidic solutions. These observations may reflect the effects of adenine protonation and the consequent coulombic interactions between it and the charged electrode surface. A third FAD orientation is observed (Stage III) after some time in acidic solutions, possibly involving a bilayer or a multilayer adsorbed on the mercury electrode surface.

\section{INTRODUCTION}

In our previous work concerning the adsorption of flavin adenine dinucleotide (FAD) at mercury electrodes [1], it was shown that, in $\mathrm{pH} 7$ solutions, three distinct and reproducible stages of adsorption are observed by both cyclic voltammetry (CV) and ac voltammetry. On the basis of the ac capacitive currents, the charge density (coverage) calculated from the $\mathrm{CV}$ experiments, and the peak

\footnotetext{
${ }^{1}$ Chemistry Department, Assiut University, Assiut, Egypt.

"To whom correspondence should be addressed.

0022-0728/92/\$05.00 (c) 1992 - Elsevier Sequoia S.A. All rights reserved
} 

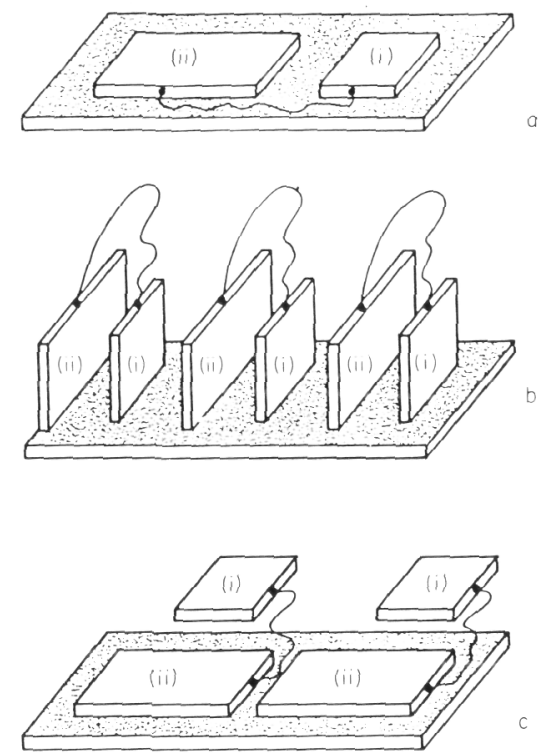

Fig. 1. Proposed orientations (from [1]) of adsorbed FAD at mercury electrodes in (a) Stage I, (b) Stage II, and (c) Stage III.

shapes and positions, it was hypothesized that, first, the isoalloxazine and adenine moieties are both adsorbed parallel to the mercury surface, leading to the development of a comparatively dilute surface layer (Stage I) independent of the potential. At a critical coverage and at potentials near the point of zero charge (pzc), both the isoalloxazine and adenine groups were suggested to take on a perpendicular orientation (Stage II), while after long cycling times over a wide range of potential, a unique third stage of adsorption (Stage III), exhibiting a higher surface concentration but otherwise more similarity to Stage I, is seen. These three proposed orientations are shown schematically in Fig. 1 [1].

Analogous studies have now been carried out in acidic solutions. Part of the motivation for this has been the general interest in monitoring and studying the individual one-electron reactions of flavins [2-6], as well as metal ion complexation with the semiquinone form, reported to occur more readily in acidic environments. In addition, it was of interest to determine the influence of adenine protonation on the adsorption behavior of FAD. Finally, the electrochemistry of adsorbed flavins at mercury electrode surfaces is relatively unique in terms of the range of orientations which can be reproducibly obtained for a redox-active adsorbate as a function of a number of important experimental variables. Therefore the study of these systems offers an important opportunity to probe the adsorption of electroactive species when controllable coulombic and steric factors are involved, and possibly to extrapolate these results to biologically relevant environments.

In the present work, we have investigated the $\mathrm{pH}$ range from ca. 2 to 7 . It is shown that the protonation of the adenine moiety at $\mathrm{pH} \lesssim 4.5$ strongly influences 
FAD adsorption. We offer a model of the orientations of FAD, based principally on our earlier ideas [1] but extended for the conditions studied here. It is anticipated that in the near future these hypothesized configurations of adsorbed flavins will be tested by in situ spectroscopic investigations.

EXPERIMENTAL

Equipment

Standard three-electrode potentiostatic circuitry was employed, utilizing a PAR 173 potentiostat and a 175 universal programmer for the CV and ac voltammetry experiments, for which a PAR 5206 lock-in amplifier was also employed. The ac experiments typically involved a voltage amplitude of $5 \mathrm{mV}(\mathrm{pp})$, a frequency of $330 \mathrm{~Hz}$, a phase angle of $90^{\circ}$, and a $5 \mathrm{mV} \mathrm{s}^{-1}$ scan rate, while a wide range of sweep rates was used for the CV experiments. All data were plotted on an SE 780 BBC $X-Y$ recorder or an HP 7090 A digital plotter.

\section{Cell and solutions}

All experiments were carried out in the standard cell provided with the PAR 303 hanging mercury drop electrode (HMDE) system. The HMDE was operated on the medium setting throughout this work, resulting in a surface area of ca. 0.015 $\mathrm{cm}^{2}$. $\mathrm{An} \mathrm{Ag} / \mathrm{AgCl}(4 \mathrm{M} \mathrm{KCl}$ containing saturated $\mathrm{AgCl}$ ) electrode served as the reference electrode and a platinum wire as the counter-electrode. All potentials are given versus the $\mathrm{Ag} / \mathrm{AgCl}$ reference electrode.

The experiments were carried out using Britton-Robinson buffer solutions in the range of $\mathrm{pH}$ from 1.8 to 10.0 , while another series of unbuffered solutions of $\mathrm{pH} 1.5-3$ were made up with sulfuric acid and sodium sulfate. FAD was obtained as its sodium salt from Sigma Chemicals Co. The flavin solution concentrations ranged from $5 \times 10^{-7}$ to $4 \times 10^{-5} \mathrm{M}$, although the bulk of the results reported here were obtained in $2 \times 10^{-6} \mathrm{M}$ FAD. All chemicals were of reagent grade and water was triple distilled. The cell solution was deaerated by bubbling nitrogen either through or above the solution during the experimental runs. All experiments were carried out at room temperature $\left(22 \pm 1^{\circ} \mathrm{C}\right)$.

\section{RESULTS AND DISCUSSION}

The study of the adsorption behavior of FAD at mercury electrode surfaces in acidic solutions was carried out in relatively dilute FAD solutions (ca. micromolar) and at relatively high scan rates (e.g. $100 \mathrm{mV} \mathrm{s}^{-1}$ ) in order to enhance the FAD adsorption currents relative to the diffusion-controlled ones. The HMDE was used in all of this work because a fresh reproducible mercury surface could be produced readily at controlled intervals. Adsorbed flavins are extremely difficult to remove 
from mercury electrochemically [1], and hence a new mercury surface was required after each experiment.

\section{Determination of state of charge of adsorbed FAD}

An initial goal of this study was to elucidate the $\mathrm{pH}$ conditions and the FAD oxidation state at which adsorbed FAD, both in the oxidized and reduced forms, is cationic, neutral or anionic, i.e. to determine the $\mathrm{p} K_{\mathrm{a}}$ of adsorbed FAD, particularly in its different orientations. This is of importance in terms of the interpreta. tion of the electrochemistry of adsorbed FAD in the light of adsorption strength and interactions with the charged electrode surface.

The oxidation-reduction properties of flavin compounds in solutions of varying $\mathrm{pH}$ (riboflavin (RF), flavin mononucleotide (FMN) and FAD) have been investigated previously, primarily by potentiometry and polarography [6-12]. By tracking the half-wave potential in the latter case, three regions of the $\mathrm{pH} /$ potential plot have been distinguished. In both acidic and basic solutions, the slope is ca. $60 \mathrm{mV}$ per $\mathrm{pH}$ unit, i.e. both the oxidized and reduced forms of FAD bear an identical charge, while in neutral and weakly basic solutions, $\mathrm{d} E / \mathrm{dpH}$ is ca. $30 \mathrm{mV}$, indicating that deprotonation occurs during the reduction reaction.

Based on these prior results, both forms of solution FAD have been suggested to be uncharged from $\mathrm{pH}$ ca. 0 to $6-6.5[6-8,10,11]$. At all $\mathrm{pH}$ values greater than this, the reduced form is deprotonated, while at $\mathrm{pH} \gtrsim 10$, the oxidized form also loses a proton. Both the oxidized and reduced forms of the isoalloxazine system in solution can apparently be protonated at $\mathrm{pH} \leqslant 0$ [7]. It is also of interest that the one-electron reduction product, the semiquinone intermediate, is expected to be neutral in the range of $\mathrm{pH}$ from $1-3$ to ca. 6.5.

There have been only two prior studies reported in the literature $[13,14]$ regarding the $\mathrm{p} K_{\mathrm{a}}$ of adsorbed flavins, and in these no attention was paid to the orientation of the adsorbate. The $E-\mathrm{pH}$ plot for adsorbed FAD at a graphite electrode [13] yielded a slope of $60 \mathrm{mV}$ from $\mathrm{pH}$ ca. 1 to $\mathrm{pH}$ ca. 8.0, versus $\mathrm{pH}$ ca. 6.5 in solution. In another study [14], riboflavin, attached via a mercaptopropyl linkage to a gold electrode, displayed changes in slope at pH 6.2 and at pH 10.5, similar to the solution case.

Figure 2 shows a typical series of CVs observed in a pH 6.4 solution with continuous cycling of the potential. Stages I and II can readily be seen, the first characterized by a broad pair of small peaks and the second by narrower ones at higher coverages. Stage III is characterized by the very broad peaks which develop after long cycling times. It is important to note that, as expected, the individual one-electron steps cannot be distinguished at this $\mathrm{pH}$, even at very high sweep rates [1].

In order to establish the $\mathrm{p} K_{\mathrm{a}}$ of adsorbed FAD in the present work, the Stage I peaks were selected. These peaks are present over the entire $\mathrm{pH}$ range, they exhibit no kinetic limitations up to sweep rates greater than $500 \mathrm{mV} \mathrm{s}^{-1}$ [1] and their shape is independent of experimental variables such as time, potential limits 


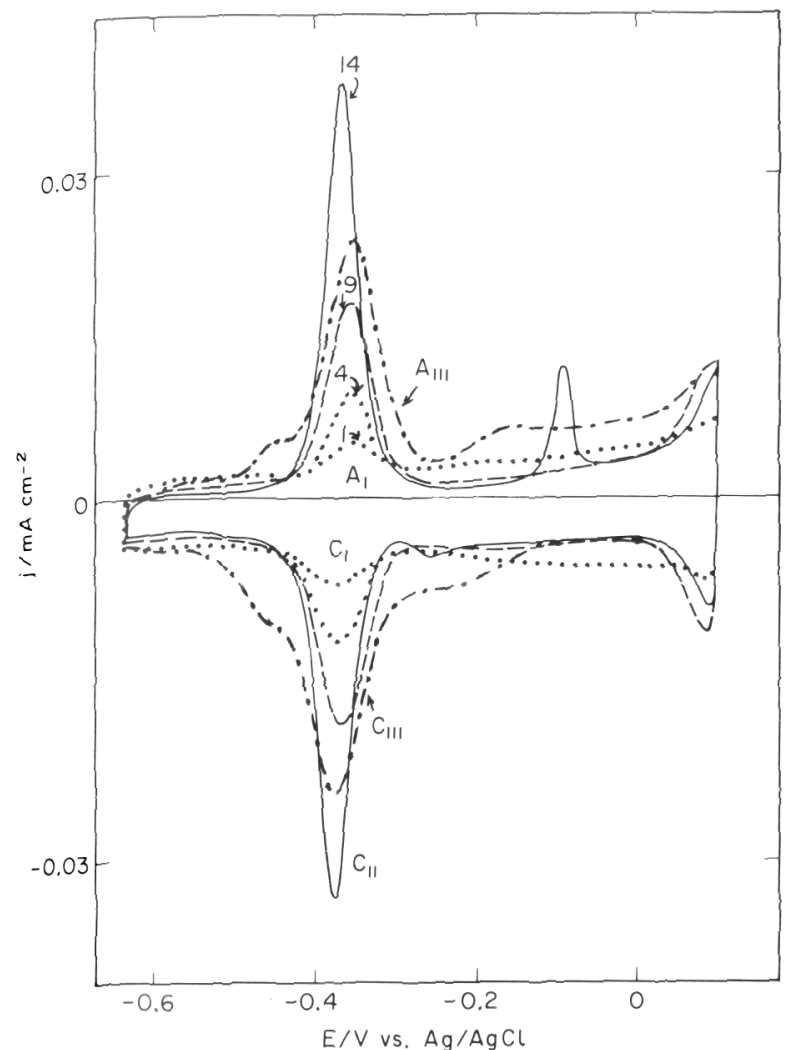

Fig. 2. Sequence of $\mathrm{CVs}$ obtained at $s=100 \mathrm{mV} \mathrm{s}^{-1}$ at a fresh mercury surface in $\mathrm{pH} 6.4$ solution.

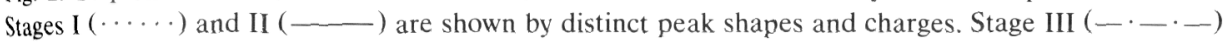
is obtained after ca. $100 \mathrm{~min}$ of potential cycling. Only some cycle numbers are shown. FAD concentration, $2 \mu \mathrm{M}$.

etc. The $\mathrm{pH}$ dependence of Stages II and III of adsorption were also examined (see below).

It can be seen in Fig. 2 that, at $\mathrm{pH}$ 6.4, as the Stage I peaks increase in size with increasing FAD coverage, the peak potentials remain relatively constant (a slight negative shift of the anodic peak is actually observed), while at lower $\mathrm{pH}$ values both peaks shift positively with increasing FAD coverage. Because of these small changes which occur with time of deposition in Stage I, the $\mathrm{pH}$ dependence of the Stage I peaks was monitored both in the first scan and just prior to the conversion of Stage I to Stage II. Again, it is noteworthy that the Stage I peaks do not deconvolute into two peaks, representative of two one-electron transfer steps, even at $\mathrm{pH} 2$ and sweep rates of up to $500 \mathrm{mV} \mathrm{s}^{-1}$.

Figure 3 shows that, superficially, the $\mathrm{pH}$ dependence of the oxidation-reduction peaks of adsorbed FAD (Stage I) is ca. $60 \mathrm{mV}$ from $\mathrm{pH}$ ca. 2-7, i.e. the 


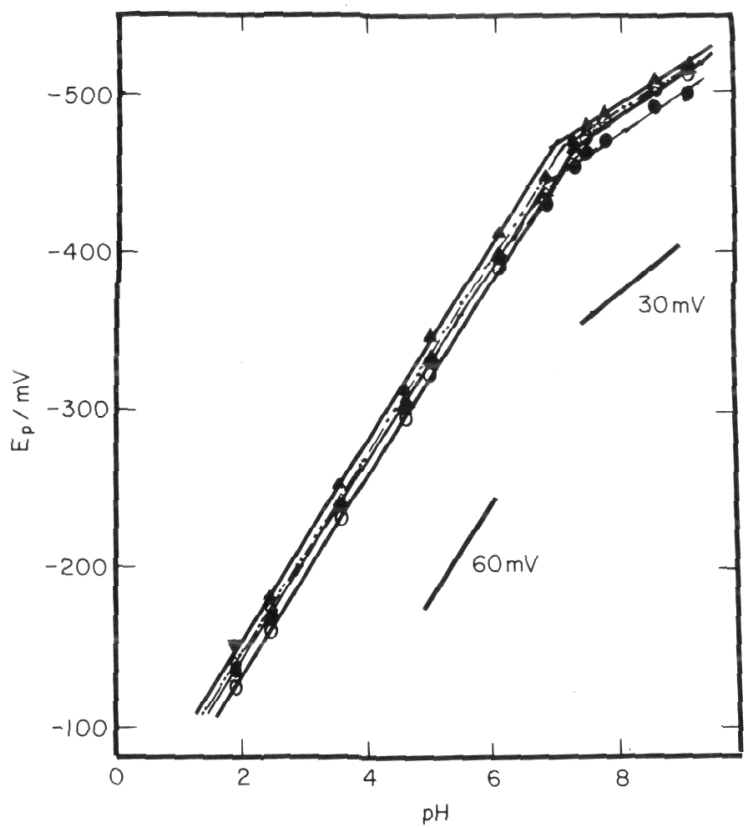

Fig. 3. $\mathrm{pH}$ dependence of the oxidation-reduction reaction of adsorbed FAD in Stage I $(s=100 \mathrm{mV}$ $\mathrm{s}^{-1}$ ) in the first cyclè of potential ( anodic; cathodic) and just prior to conversion to Stage II ( 0 anodic; $\triangle$ cathodic). FAD concentration, $2 \mu \mathrm{M}$.

isoalloxazine system is neutral in this $\mathrm{pH}$ range. A closer inspection of these data shows that the $\mathrm{p} K_{a}$ determined from the first scan is ca. 6.8, while, as the coverage increases, both $\mathrm{p} K_{2}$ values shift towards 7.3. This is an indication of the gradual change of the properties of FAD as the surface concentration builds up and the FAD environment becomes less solution-like. The fact that the $\mathrm{p} K_{\mathrm{a}}$ of adsorbed FAD is generally larger than that in solution may reflect the interaction of the $\pi$-electron system of the adsorbate with the electrode, in agreement with the suggested flat orientation of FAD in this stage of adsorption (Fig. 1).

Because of the shifting $\mathrm{A}_{I I} / \mathrm{C}_{1 I}$ peak positions as a function of potential limits, scan rate etc. in acidic solutions, the above study could not be carried out rigorously for Stage II of adsorption. Nevertheless, it is likely that the isoalloxazine system will also be neutral in the acidic solutions under study. This hypothesis is supported by the similar pH dependence of the Stage III and Stage I peaks, i.e. the $\mathrm{pH}$ dependence of Stage III changes from ca. 60 to ca. $30 \mathrm{mV}$ per $\mathrm{pH}$ unit at a pH of ca. 7.5-8, similar to that reported for adsorbed FAD at glassy carbon electrodes [13] where very broad peaks, similar to those of Stage III, are seen.

It should be noted that as the pzc of mercury is expected to be at ca. $-0.42 \mathrm{~V}$ versus the $\mathrm{Ag} / \mathrm{AgCl}$ electrode [15] at $\mathrm{pH} \lesssim 6.5$, the $\mathrm{FAD}$ redox process will occur at a positively charged electrode surface, while at $\mathrm{pH}$ values greater than this it will occur at a negative surface (Fig. 3). It will be seen later in this paper and in a 


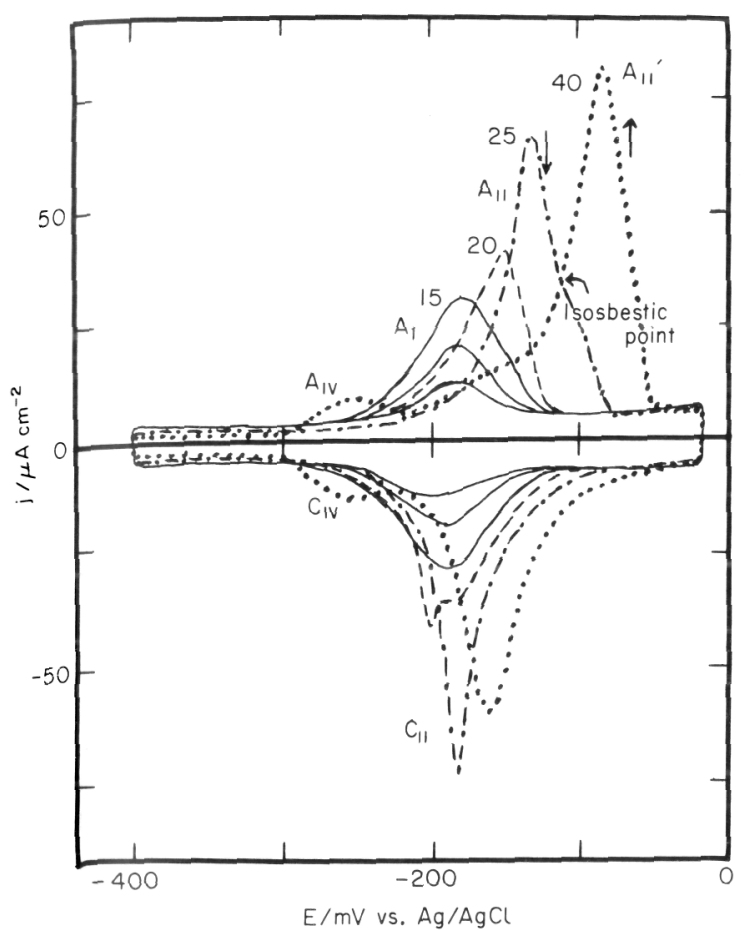

Fig. 4. CVs obtained with time of cycling at a fresh mercury electrode in $2 \mu \mathrm{m}$ FAD solution, $\mathrm{pH} 3.29$, $s=200 \mathrm{mV} \mathrm{s}^{-1}$. Some cycle numbers are shown.

subsequent paper [16], which focuses on alkaline conditions, that the interplay between the net charge on the isoalloxazine ring and on the adenine group, due to their protonation-deprotonation, and the charge on the electrode surface is important in influencing the FAD adsorption process.

General electrochemical behavior at $\mathrm{pH}$ ca. 2-5

The CV response of a fresh mercury electrode exposed to a $\mathrm{pH} 3.29,2 \mu \mathrm{M}$ FAD solution is shown in Fig. 4. The behavior at this $\mathrm{pH}$ is typical of that seen in the $\mathrm{pH}$ range under consideration in this section. Both the oxidized and reduced forms of the iso-alloxazene system are neutral (Fig. 3), while, according to the results of solution studies [7,17], the adenine moiety may now be protonated. In Fig. 4 the potential has not been extended negative of $-0.4 \mathrm{~V}$, so that the mercury surface can be envisaged as being positively charged in this particular experiment. Under these conditions, the coulombic interactions between the adenine end of the adsorbate and the electrode surface are most likely repulsive in nature. 


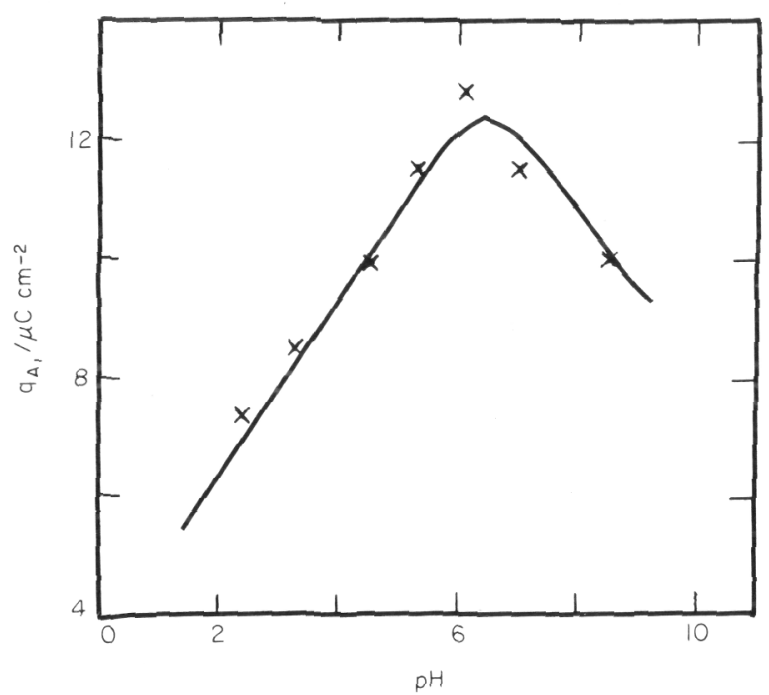

Fig. 5. Charge density in peak $\mathrm{A}_{\mathrm{I}}$ just prior to conversion to Stage II $\left(2 \mu \mathrm{M} \mathrm{FAD}, s=100 \mathrm{mV} \mathrm{s}^{-1}\right)$ as a function of solution $\mathrm{pH}$.

As in pH 6.4 solutions (Fig. 2), FAD adsorption can be seen to occur initially in the Stage I mode. The width of the $A_{I} / C_{I}$ peaks is ca. 55-60 mV throughout the $\mathrm{pH}$ range $2-5$. Figure 4 shows that, at $\mathrm{pH} 3.29$, peaks $\mathrm{A}_{\mathrm{I}} / \mathrm{C}_{\mathrm{I}}$ move positively with increasing surface coverage (up to cycle 20) in this acidic solution. Also, an examination of the charge densities in the Stage I peaks (Fig. 5, $2 \mu \mathrm{M}$ FAD) just prior to the transformation to Stage II shows that the final structure of Stage I is more dilute at low versus neutral $\mathrm{pH}$. Assuming that the adenine system is co-adsorbed at the electrode surface in Stage I (Fig. 1), full coverage has been calculated [1] to yield a maximum of ca. $14 \mu \mathrm{C} \mathrm{cm}^{-2}$, close to that seen in neutral solutions (Fig. 5). The lower coverage observed at lower $\mathrm{pH}$ is consistent with the anticipated effect of coulombic repulsion between adjacent positively charged adenine groups and/or between the adsorbate and the electrode surface. Also, steric/ coulombic factors caused by anion complexation of adenine may be playing a role at low $\mathrm{pH}$ values.

The ac voltammogram obtained in Stage I of FAD adsorption (confirmed to be the right conditions for achieving Stage I by carrying out a $5 \mathrm{mV} \mathrm{s}^{-1} \mathrm{CV}$ run at a fresh mercury electrode) displays a single pseudocapacitance peak centered at the FAD redox potential (Fig. 6, curve b), with currents which become progressively lower than those observed in the supporting electrolyte (curve a) on either side of the peak, reflecting the gradual coverage of the electrode surface with time. A capacitance "pit" is not observed at this stage of adsorption. The electroactive isoalloxazine system is likely to be adsorbed in a parallel orientation (Fig. 1) at this stage of adsorption at all potentials, while the orientation of the adenine groups is also considered to be flat. 


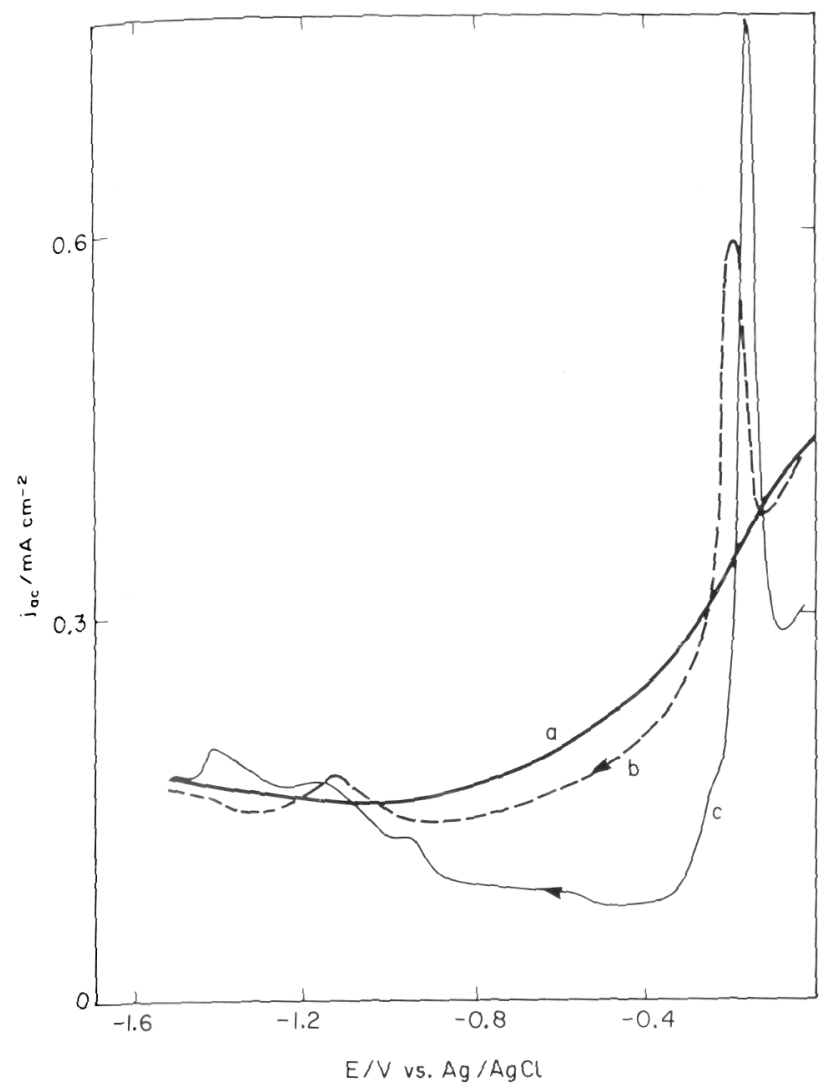

Fig. 6. ac response in pH 3.29 solution $\left(s=5 \mathrm{mV} \mathrm{s}^{-1}\right)$ in the supporting electrolyte (curve a), in $1 \mu \mathrm{M}$ FAD solution (first cathodic scan, Stage I, curve b) and in the second cathodic scan (Stage II, curve c).

In approximately the twentieth cycle in Fig. 4, the anodic peak begins to shift positively (in contrast with the case in neutral solutions, in which the Stage II peaks are negative of Stage I [1]) to ca. $-135 \mathrm{mV}$ and sharpen (peak $\mathrm{A}_{\text {II }}$ ), and the charging current negative of the peaks decreases noticeably. At the positive side of peak $\mathrm{A}_{\mathrm{II}}$, the peak broadens somewhat and the charging current is seen to be relatively large again, i.e. similar to that in Stage I. On the negative scan, the reduction peak is now characterized by a transition from broad to narrower (to Stage II) as the reduction process occurs. The corresponding ac response to this is seen in Fig. 6 (curve c); a capacitance pit is now clearly observed at potentials negative of and just into the redox peaks, with a small capacitance peak at ca. $-0.95 \mathrm{~V}$. The ac capacitance current is relatively large at potentials positive of the redox potential, even after long experiment times.

With further potential cycling, another significant change occurs in the $\mathrm{CV}$ response, as seen in Fig. 4. Peak $\mathrm{A}_{\mathrm{II}}$ diminishes in size, and a new peak at ca. 
$-0.09 \mathrm{~V}$ (peak $\mathrm{A}_{I^{\prime}}$ ) develops via an isosbestic point, clearly indicating the transformation of one form of the adsorbate to another. Furthermore, the cathodic peak now broadens slightly and moves ca. $10 \mathrm{mV}$ positively $\left(\mathrm{C}_{\mathrm{II}^{\prime}}\right)$, a new pair of small peaks $\left(\mathrm{A}_{\mathrm{IV}} / \mathrm{C}_{\mathrm{IV}}\right)$ develop at ca. $-0.27 \mathrm{~V}$, a small anodic peak often remains at ca. $-0.16 \mathrm{~V}$ and the charging current decreases further at negative potentials.

The results shown in Figs. 4 and 6, which are representative of the $\mathrm{pH}$ range from 2 to ca. 4.5-5 when the isoalloxazine ring system is neutral and adenine is probably protonated, can be summarized as follows. Stage I, in which the isoalloxazine moiety is believed to be parallel to the electrode surface, is stable at all potentials. With increasing coverage in Stage I, steric factors cause both peaks to move a little positively; this will be discussed further below. At a critical coverage, which increases with $\mathrm{pH}$, a perpendicular orientation (Stage II) is taken on. This is stable until the film is partially or substantially oxidized (at positive potentials) and then the film reorients to a parallel form. During the negative scan, the film reverts to a perpendicular orientation during the reduction process. The ease of this conversion increases with increasing coverage, as seen by the progressive positive shift in potential of the broad to sharn transition in the $C_{\mathrm{rr}}$ peak in Fig. 4 . If the potential is maintained near or positive of the pzc, another adsorption stage

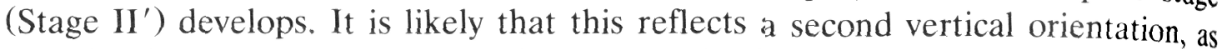
seen by the narrowness of the II' peaks, indicative of strong lateral interactions within the surface layer and the even smaller charging currents at negative potentials (consistent with a deeper capacitance pit). The significance of peaks $\mathrm{A}_{\mathrm{IV}} / \mathrm{C}_{\mathrm{IV}}$ will be discussed further below.

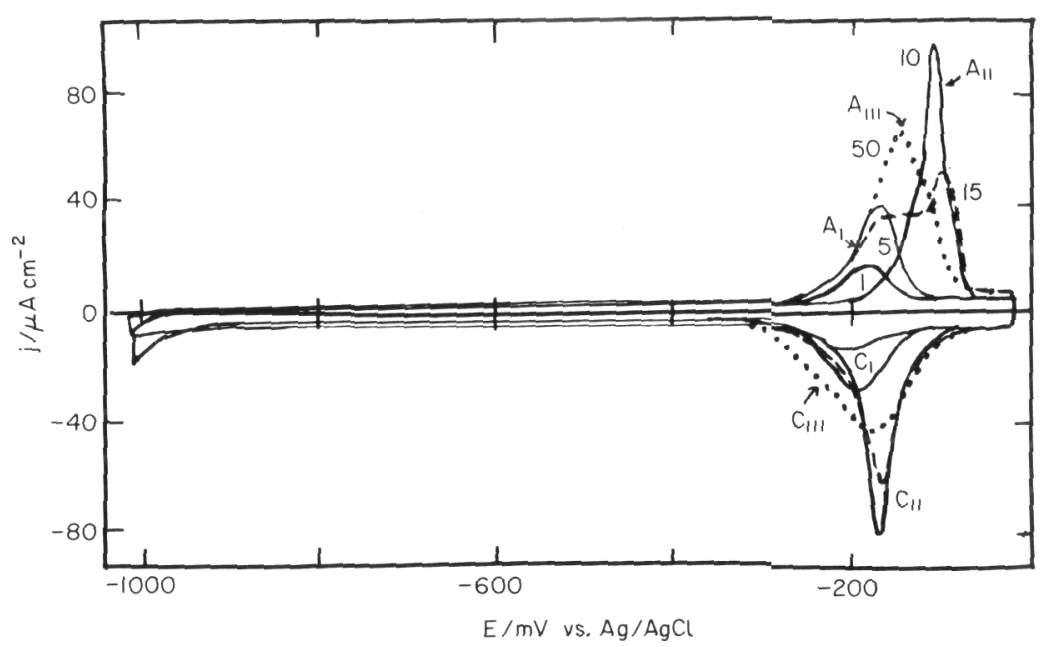

Fig. 7. CVs obtained under identical conditions to those in Fig. 4, but when the negative potential limi is $-1 \mathrm{~V}$ : - Stage I; . . . . Stage II, … Stage III after many cycles. $s=200 \mathrm{mV} \mathrm{s}^{-1}$. Som cycle numbers are shown on the figure. 


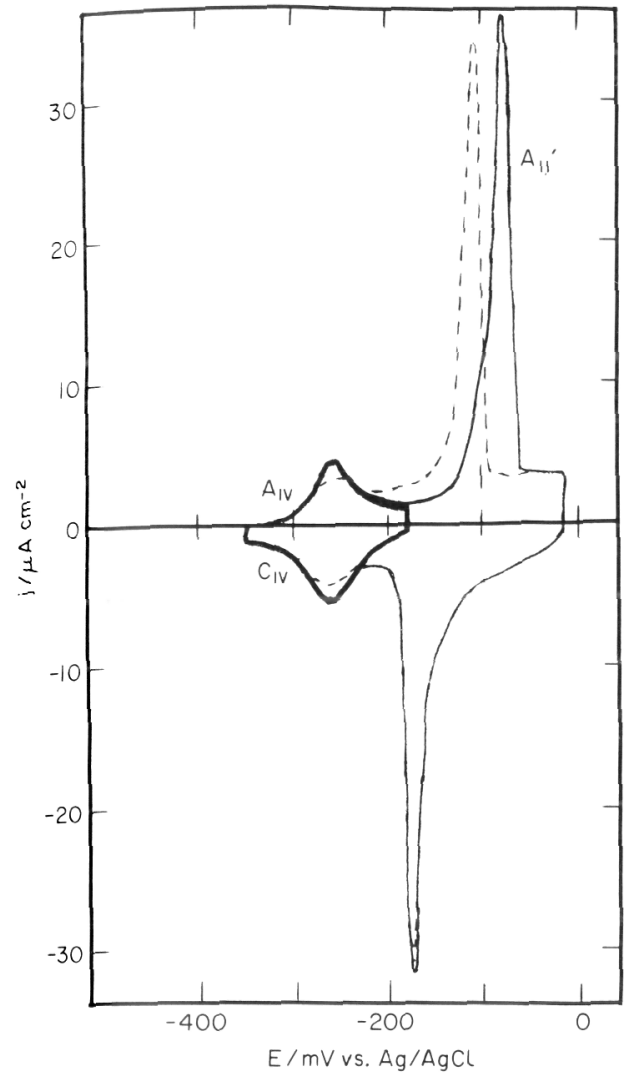

Fig. 8. CV response (— - obtained immediately after $5 \mathrm{~min}$ of continuous cycling $\left(s=60 \mathrm{mV} \mathrm{s}^{-1}\right)$ over restricted potential range of $\mathrm{A}_{\mathrm{IV}} / \mathrm{C}_{\mathrm{IV}}$. Second scan of potential (- . - ). $2 \mu \mathrm{M} F A D, \mathrm{pH}=3.3$.

Figure 7 shows the impact of the lower potential limit on the stability of Stages II and II'. When the lower limit is extended to ca. $-1.0 \mathrm{~V}$, the Stage II peaks transform directly to a response typical of Stage III. These results suggest that Stage II', not observed under any conditions at near-neutral and alkaline $\mathrm{pH}$ values, is induced by repulsive interactions between a relatively concentrated layer of adsorbed FAD, probably charged positively at the adenine group at this $\mathrm{pH}$, and the positively charged electrode. This is demonstrated more clearly in Fig. 8. When the potential is cycled continuously over a restricted range of potential from -0.35 to $-0.18 \mathrm{~V}$ for ca. $10 \mathrm{~min}$, peaks $\mathrm{A}_{\mathrm{IV}} / \mathrm{C}_{\mathrm{IV}}$ become quite pronounced. When the upper limit is then increased to almost $0 \mathrm{~V}$, the Stage $\mathrm{II}^{\prime}$ peak can be seen to be large and sharp. In fact, the charge density in $\mathrm{A}_{\mathrm{II}}\left(\mathrm{ca} .15 \mu \mathrm{C} \mathrm{cm}^{-2}\right)$ is greater than is usually observed in Stage II at this $\mathrm{pH}$ (ca. $13 \mu \mathrm{C} \mathrm{cm}^{-2}$ ), indicating that a higher FAD surface coverage was achieved than in continuous cycling experiments.

A number of features of the ac voltammograms, seen in Stage II in acidic solutions, are also worthy of closer consideration. Figure 6 shows that the negative 
end of the capacitance pit is ca. $-1.1 \mathrm{~V}$ at $\mathrm{pH}$ less than ca. 4.5. However, at higher $\mathrm{pH}$ values, the limit of the pit is constant at ca. $-0.85 \mathrm{~V}$ [1]. The small peak at ca. $-0.95 \mathrm{~V}$, referred to above, is seen only at $\mathrm{pH}$ less than ca. $4.5-5$, when the pit is sufficiently wide, and is never seen in Stage I of adsorption.

An analysis of the small peak at ca. $-0.95 \mathrm{~V}$ in Fig. 6 in terms of its phase angle and frequency dependence shows that it is purely capacitive in nature, and therefore probably reflects further orientational changes of the adsorbate, perhaps induced by the adenine group. A similar nonfaradaic peak is seen at ca. $-0.9 \mathrm{~V}$ versus the saturated calomel electrode (SCE) in the out-of-phase ac voltammograms of adenine oligonucleotide [18], and at $-0.95 \mathrm{~V}$ versus SCE (at $\mathrm{pH} 3.4$ ) for adenine monophosphate $[19,20]$, where it was ascribed to the reorientation of phosphate residues in the condensed film adsorbed at the mercury electrode surface.

The involvement of adenine in the small peak at $-0.95 \mathrm{~V}(\mathrm{pH} 3.3)$ is supported by the fact that the peak is absent in the ac response of lumiflavin (LF) [21], which consists of only the isoalloxazine ring system and a methyl group attached at the $\mathrm{N}(10)$ position, under the same conditions, even though the electrochemistry of LF adsorption is otherwise very similar to that of FAD. It is also important that the peak is not observed at $\mathrm{pH}$ 5.1, when, from solution studies, the adenine ring is expected to be neutral $[7,17,22]$. These results support the hypothesis that this small peak reflects an FAD reorientation process involving adenine, perhaps induced by the interaction of the positively charged adenine group with the negative electrode surface.

At potentials negative of the pit, the a.c. current rises above that of the supporting electrolyte (Fig. 6). However, FAD is not desorbed, as seen by the fact that holding the potential at $-1.1 \mathrm{~V}$ for 5 min does not lead to loss of charge at this $\mathrm{pH}$. Instead, only a broadening of the anodic peak is observed, consistent with Fig. 7. The a.c. peak observed at ca. $-1.15 \mathrm{~V}$ (Fig. 6) is similar to that seen previously for all bases [23-25], nucleosides [23,26] and nucleotides [17-20,26,27] contained in nucleic acids, as well as for DNA $[28,29]$ and polyadenylic acid [30] at the same potential. This peak has been suggested to reflect a further reorientation of the adsorbate. Another peak is seen at ca. $-1.45 \mathrm{~V}$ (Fig. 6), which has been described previously as reflecting the reduction of the adenine moiety [17].

The presence of adenine electrochemistry in the ac voltammograms of Stage II (Fig. 6) strongly supports the contention that adenine is directly in contact with the electrode surface in this orientation. This rules out a configuration at negative potentials in which the isoalloxazine group is on the electrode surface, but with the adenine group in solution. This may be the structure of Stage II', but II' is not stable in this potential range. These results support our earlier suggestion [1] of a stacked orientation of FAD in Stage II of adsorption (Fig. 1).

Similar to the case at $\mathrm{pH} 7$ [1], further changes in the CV response of adsorbed FAD occur with time of cycling over an extended potential range, i.e. particularly from ca. $0 \mathrm{~V}$ to potentials negative of ca. $-1.0 \mathrm{~V}$. Under these conditions (Fig. 9(a)), charge densities increase to ca. $30 \mu \mathrm{C} \mathrm{cm} \mathrm{cm}^{-2}$, the $\mathrm{CV}$ peaks broaden 

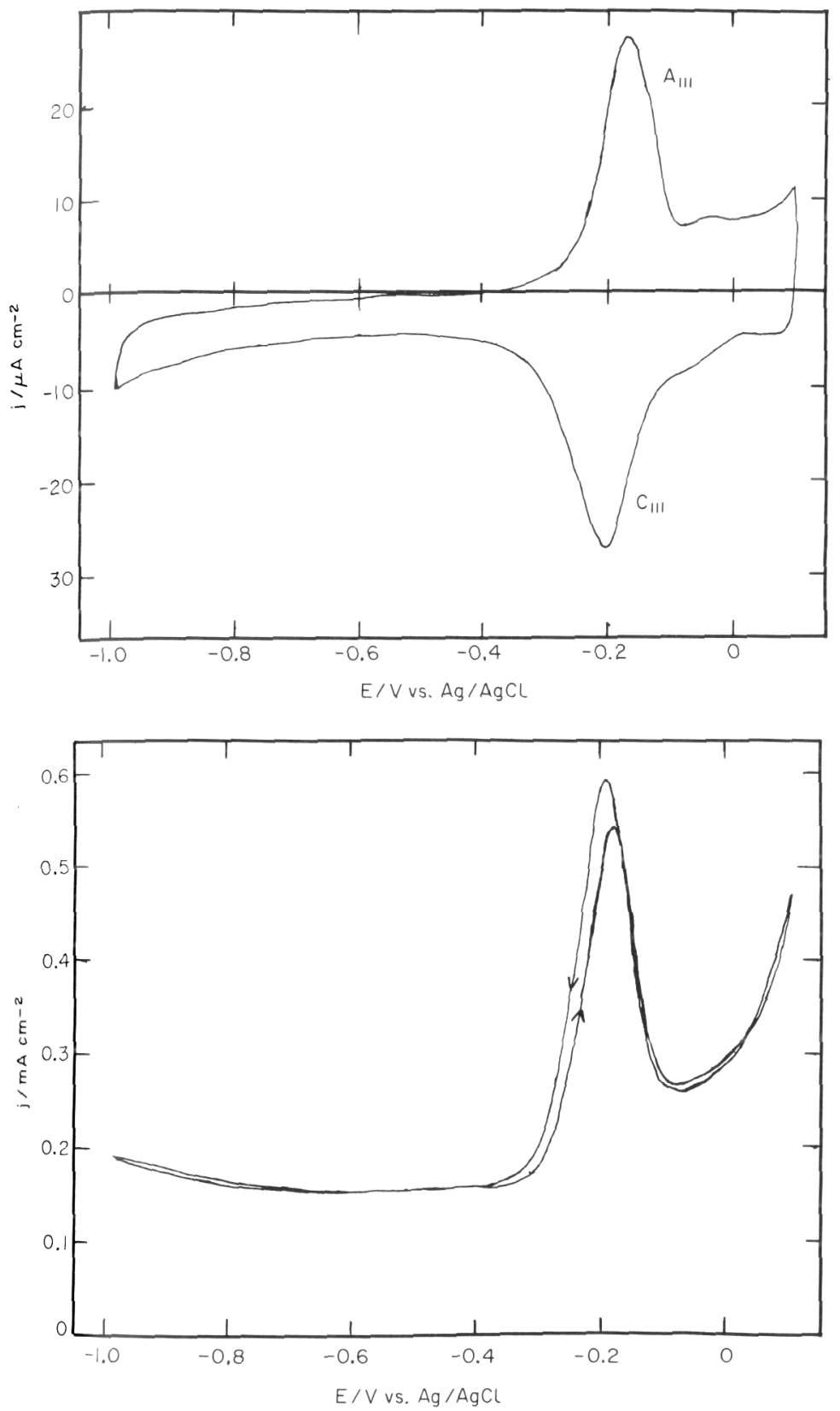

Fig. 9. (top) CV response of Stage III after 60 min potential cycling in $1 \mu \mathrm{M}$ FAD solution ( $\mathrm{pH} 3.8$, $s=100 \mathrm{mV} \mathrm{s}^{-1}$ ); (bottom) ac response for FAD under the same conditions as (a) $\left(s=5 \mathrm{mV} \mathrm{s}^{-1}\right)$. 
$\left(w_{1 / 2} \approx 100 \mathrm{mV}\right)$ and the ac response (Fig. 9(b)) no longer displays a capacitance pit. Also, no remaining signature for adenine on the electrode surface is seen at negative potentials in the ac response under these conditions, probably indicating that the adenine group is no longer in direct contact with the electrode, as suggested in Fig. 1. As can be seen in Fig. 9(a), some of the anodic charge density is contained in a broad region positive of the main redox peaks.

These results reflect Stage III of FAD adsorption [1], which may involve the formation of a parallel condensed adsorbed layer (Fig. 1). It should be noted that a tightly packed layer of the structure shown in Fig. 1 for Stage III could contain up to the equivalent of ca. $21 \mu \mathrm{C} \mathrm{cm}^{-2}$ of charge. The fact that the Stage III charge densities are even larger than this implies that the structure of Stage III involves more than one monolayer, perhaps consistent with the broad appearance of the peaks and the slower kinetics observed (see below).

\section{Sweep rate dependence of Stages I and III}

As mentioned above, Stage I of FAD adsorption displays a persistent potential difference between the anodic and cathodic peaks, despite the fact that no evidence for adsorbate reorientation is observed at any potential during scanning. Figure 10(a) shows that, at $\mathrm{pH} 3.8$ for example, the peak separation $\Delta E_{\mathrm{p}}$ (the difference between $\times$ and $O$ ) is ca. $20 \mathrm{mV}$ at all sweep rates from 20 to $500 \mathrm{mV}$

$\mathrm{s}^{-1}$, except during the first few potential cycles when the surface concentration is low. The constancy of this peak separation indicates that kinetic limitations are not involved. If slow electron transfer were implicated, then $\Delta E_{\mathrm{p}}$ should increase with sweep rate [31].

The unchanging $20 \mathrm{mV}$ peak separation may be a reflection of the different conformation of the oxidized and reduced forms of Stage I (with the isoalloxazine ring system still remaining essentially parallel to the electrode surface in each case) which is not distinguishable from the $A_{1} / C_{1}$ peak shapes. This may be related to the fact that reduced isoalloxazine is known, from solution studies, to fold on the $\mathrm{N}(5)-\mathrm{N}(10)$ axis, taking on a "butterfly" configuration $[32,33]$, while the oxidized form has been shown to be planar. It has been reported previously that the former has a more positive redox potential than the latter [33], consistent with the present results. It is of interest that, at sweep rates greater than ca. $2 \mathrm{~V} \mathrm{~s}^{-1}$, the peak separation diminishes [1], perhaps indicative of insufficient time available for the butterfly-planar transformation to occur.

With increasing coverage of FAD in Stage I, the peak separation diminishes to ca. $10 \mathrm{mV}$ or less (Fig. 10(a), $\times$ versus + ) as the cathodic peak moves positively in acidic solutions. The decreasing peak separation may imply that as steric hindrances and coulombic repulsion increase with increasing FAD coverage on the electrode surface, the oxidized and reduced forms of FAD are less able to take on either a different conformation or alternate between the butterfly and planar configurations, thus diminishing the difference between the two forms. 

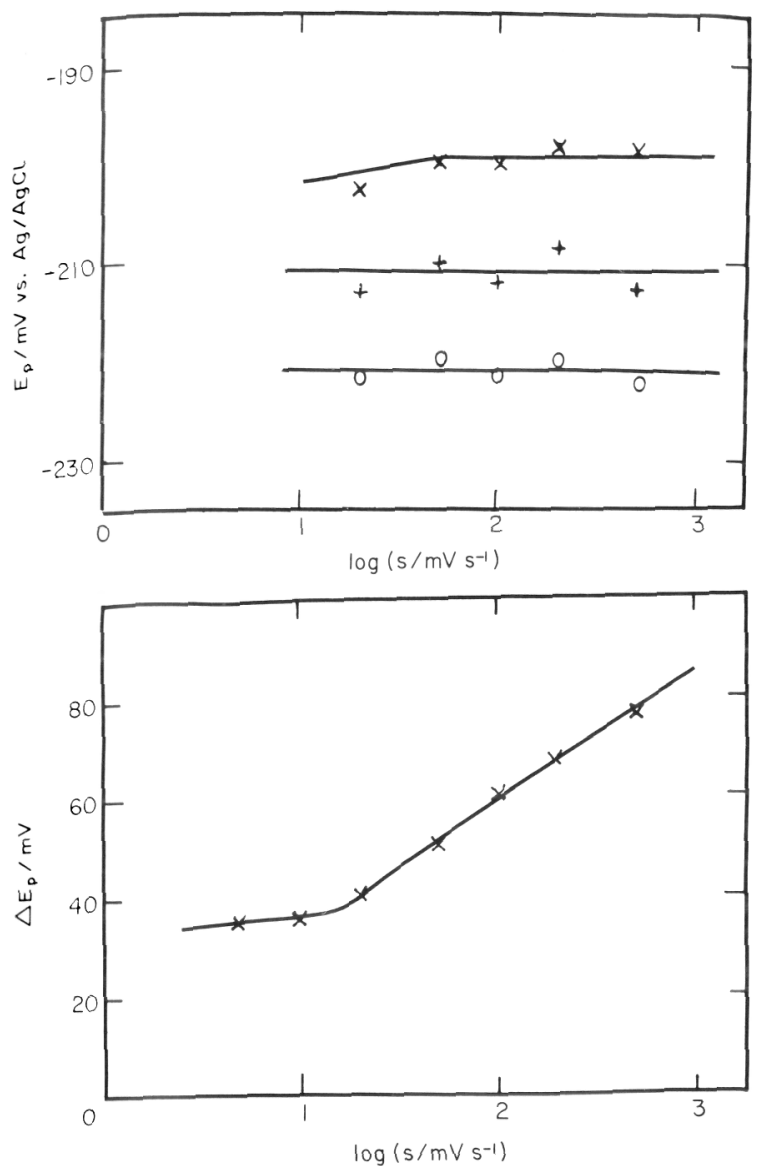

Fig. 10. (top) Stage I peak potentials in $1.7 \mu \mathrm{M}$ FAD solution ( $\mathrm{pH} 3.8, s=100 \mathrm{mV} \mathrm{s}^{-1}$ ). First scan over $A_{I}(x)$ and over $C_{I}(O)$; potentials just prior to conversion to Stage II of peak $A_{I}(\times)$ and peak $C_{I}$ $(+)$. (bottom) Separation of Stage III peaks as a function of sweep rate (1.7 $\mu$ M FAD solution, $\mathrm{pH}$ 3.8).

Persistent peak separations which are independent of sweep rate have been reported in the case of numerous polymer-modified electrode systems and have been described as reflecting unusual quasi-reversibility (UQR) [34]. It is suggested [34] that a phase transition involving large domains in the reacting phase would result in UQR, and that broad peaks imply that the domains are not identical. In the case of Stage I of FAD adsorption, such a phase transition could be the butterfly-planar transformation, while the relative breadth of these peaks (ca. 70 $\mathrm{mV}$ at half-height) could reflect the presence of large, but different, domains within the FAD layer. It is of interest that, in Stage II, the CV peaks are sharper and the peak separation is smaller, consistent with the presence of smaller, more similar domains [24]. 


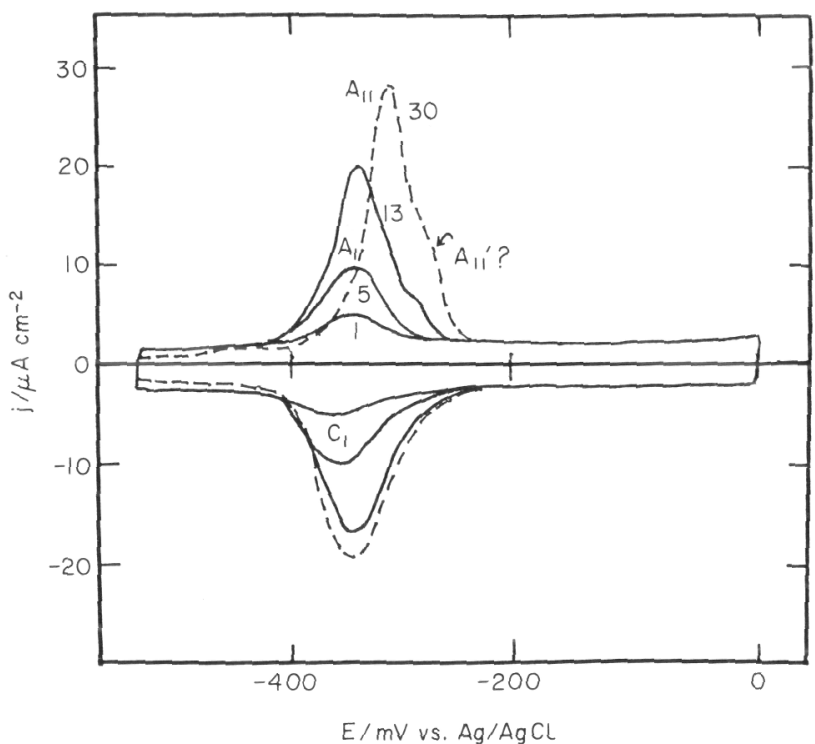

Fig. 11. CV response at a fresh mercury electrode in $2 \mu \mathrm{M}$ FAD solution ( $\mathrm{pH} 5.02, s=100 \mathrm{mV} \mathrm{s}^{-1}$ ).

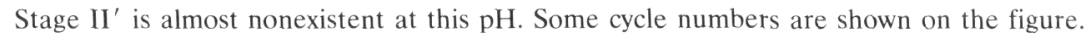

Because of the dependence of the potentials, shapes and sizes of peaks II and II' on FAD coverage, potential limits and $\mathrm{pH}$, it was not possible to analyze rigorously the dependence of this stage of adsorption on sweep rate. In comparison, the Stage III peaks can be studied in this way. The separation of the Stage III peaks was found to be quite strongly dependent on sweep rate (Fig. 10(b)), increasing by ca. $30 \mathrm{mV}$ per decade of sweep rate. This indicates that kinetic limitations are now present, in contrast to the case of Stage I and confirming that Stage III involves a substantially different structure from that of Stage I, perhaps even a FAD multilayer.

\section{Electrochemical behavior at pH ca. 5-7}

A number of changes in the $\mathrm{CV}$ and ac characteristics of the FAD adsorption process, compared with more acidic solutions, commence in the range of $\mathrm{pH} 4.5-5$. Figure 5 shows that the coverage of Stage I reaches a value of ca. $11 \mu \mathrm{C} \mathrm{cm}^{-2}$ just prior to its conversion to Stage II. At pH 4.5 the transformation of peak $\mathrm{C}_{\mathrm{II}}$ to $\mathrm{C}_{\mathrm{II}}$ is no longer seen and, by $\mathrm{pH} 5, \mathrm{~A}_{\mathrm{II}^{\prime}}$ is barely observed and the cathodic peak remains broad under all conditions (Fig. 11). This means that the positive end of the capacitance pit must now be more negative than the potential range of FAD reduction, despite the fact that the redox potential has shifted negatively with this increase in $\mathrm{pH}$. Likewise, the negative end of the capacitance pit is now ca. -0.8 $\mathrm{V}$, versus $-1.1 \mathrm{~V}$ at lower $\mathrm{pH}$ values (Fig. 6). This new behavior, including the 
relative narrowness of the capacitance pit, is interpreted as reflecting the now neutral charge of the adsorbate, i.e. that the $\mathrm{p} K_{\mathrm{a}}$ of the adenine group in FAD is ca. 4.5 .

Other changes which are seen in the $\mathrm{pH}$ range of 5-7 include the fact that, at $\mathrm{pH}$ greater than ca. 5.5-6, the $\mathrm{A}_{\mathrm{I}}$ peak potential now moves negatively with increasing $\mathrm{FAD}$ coverage, while peak $\mathrm{C}_{\mathrm{I}}$ still moves positively. At $\mathrm{pH}$ greater than ca. 6-6.5, the Stage II peaks are negative of the Stage I peaks, while at $\mathrm{pH} \approx 7$ both Stage I peaks move negatively as more FAD deposits on the electrode surface. In contrast, at $\mathrm{pH}<5.5$, all peak potentials become more positive with increasing FAD coverage, in both Stages I and II. These minor alterations in the electrochemical behavior of FAD adsorption may be related to the fact that the FAD redox potential is now near and almost negative of the pzc, and that by $\mathrm{pH} \approx 6$ a fraction of the reduced isoalloxazine will bear a negative charge. Therefore, as the $\mathrm{pH}$ increases further, new coulombic interactions between the negatively charged adsorbate and the charge of the electrode will occur.

Model of adsorbed FAD in acidic solutions

The distinctive electrochemistry of FAD at $\mathrm{pH}$ less than ca. 4.5 indicates that the adenine group of FAD has a $\mathrm{p} K_{\mathrm{a}}$ of ca. 4.5-5. When this moiety is positively charged, it has been found that the perpendicular condensed surface orientations are stabilized. This is seen by the ease of conversion of Stage I to II at low $\mathrm{pH}$ (which occurs at a lower coverage of FAD in Stage I (see Fig. 5)), the increased width of the capacitance pit, particularly to very negative potentials of ca. $-1.1 \mathrm{~V}$, and the appearance of a second vertical orientation, $\mathrm{II}^{\prime}$, characterized by very sharp and narrow $\mathrm{CV}$ peaks and a higher surface coverage than is normally achieved.

It is suggested that Stages I and II are essentially equivalent to those reported previously in neutral solutions (Fig. 1), while II' (Fig. 12) may represent the adsorption of the isoalloxazine system, possibly with its short, rather than long, end on the mercury surface and the adenine group now in solution. It is reasonable that this orientation would be more stable at positive potentials both because the adenine group is positively charged and because the negative end of the dipole of the isoalloxazine system is now pointed directly towards the positively charged electrode surface. The extrusion of the adenine group from the surface layer would lead to enhanced lateral interactions between the now adjacent isoalloxazine moieties, consistent with the larger charge densities obtained in this case and the very narrow $\mathrm{A}_{I^{\prime}}$ peak (Figs. 4 and 8).

The $\mathrm{A}_{\mathrm{IV}} / \mathrm{C}_{\mathrm{IV}}$ peaks, seen only when FAD is predominantly in the II' stage of adsorption (Fig. 8), may reflect the oxidation-reduction of FAD dimers, likely to be more readily formed when the isoalloxazine rings are adjacent to one another. These peaks are seen to an even greater extent in alkaline solutions. Flavin dimers have previously been reported to be particularly stable in basic media and at high concentrations in solution $[6,14,35]$, and therefore might be expected in the most 


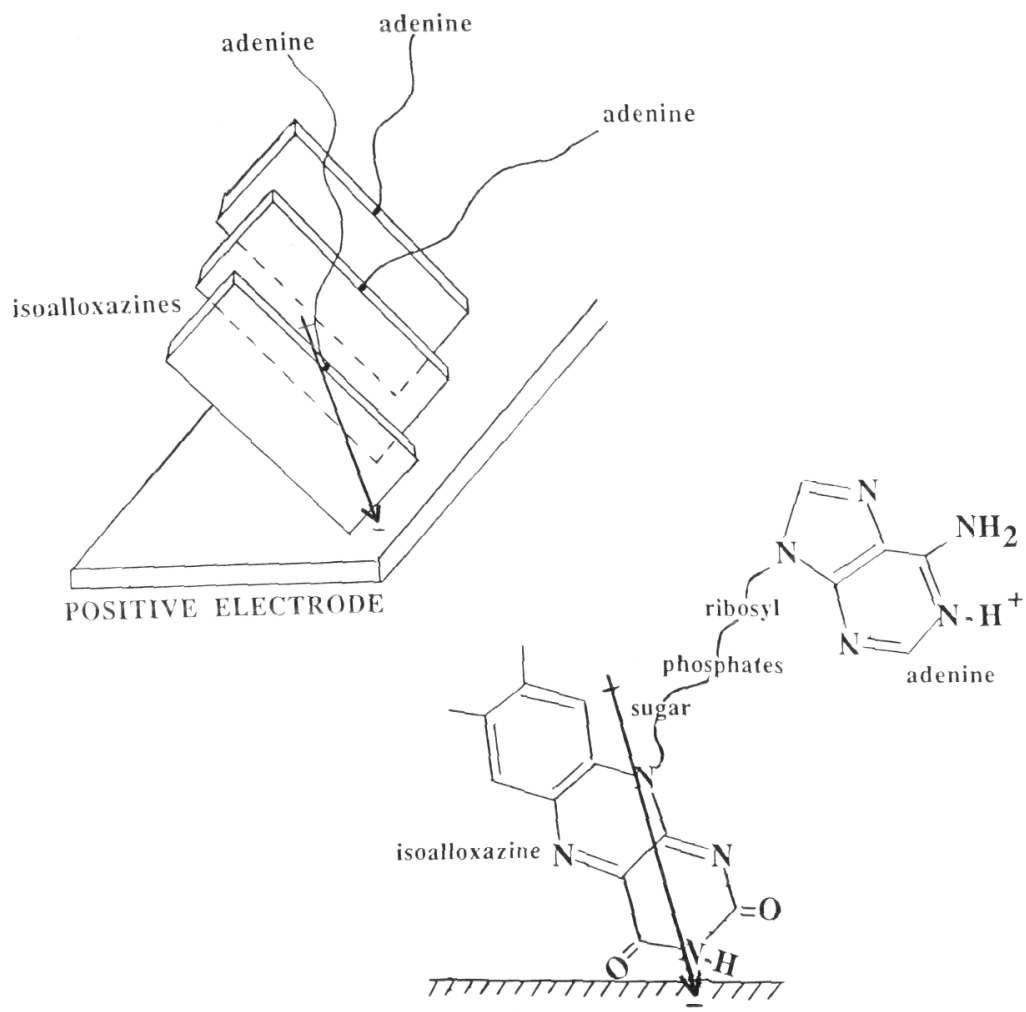

POSITIVE ELECTRODE

Fig. 12. Schematic diagram of adsorbed FAD in Stage II' in acidic solutions ( $\mathrm{pH} \lesssim 5$ ).

tightly packed surface structure obtained in this work (Stage II').

At $\mathrm{pH}$ values between 5 and 7 , Stage II' $^{\prime}$ is not seen, indicating that it was related to the positively charged adenine group. In fact, Fig. 8 demonstrates that Stage II' could be most clearly observed when the potential was cycled or held for some time at potentials positive of the pzc.

At all acidic $\mathrm{pH}$ values investigated, Stage III was the final state achievable. Its characteristic large charges and broad peaks (Fig. 9(a)), as well as the slow electron transfer kinetics observed (Fig. 10(b)) and the additional charge in the potential range positive of the redox peaks (Fig. 9(a)), may indicate that a bilayer or multilayer of FAD is forming. The fact that the ac characteristics are reminiscent of Stage I, and that no evidence for adenine reaction or reorientation is seen, supports a structure similar to that shown in Fig. 1 for Stage III, i.e. with the isoalloxazine system parallel to the electrode surface but with additional overlying FAD present. 
ACKNOWLEDGEMENTS

Grateful acknowledgement is made to the Natural Sciences and Engineering Research Council of Canada for the support of this work. We are also appreciative of the Government of Canada Award to MMK which supported his stay as a Visiting Scientist in Calgary.

REFERENCES

1 V.I. Birss, H. Elzanowska and R.A. Turner, Can. J. Chem., 66 (1988) 86.

2 A. Ehrenberg, in B. Pullman (Ed.), Electronic Aspects of Biochemistry, Academic Press, New York, 1964. pp. 379-96.

3 A.V. Guzzo and G. Tollin, Arch. Biochem. Biophys., 105 (1964) 380.

4 R.D. Braun, J. Electrochem. Soc., 124 (1977) 1342.

5 J.H. Reeves and K. Weiss, J. Electroanal. Chem., 217 (1987) 65.

6 O.S. Ksenzhek and S.A. Petrova, Bioelectrochem. Bioenerg., 11 (1983) 105.

7 B. Janik and P.J. Elving, Chem. Rev., 68 (1968) 295.

8 O.S. Ksenzhek, S.A. Petrova and I.D. Pinielle, Sov. Electrochem., 11 (1975) 1603.

9 O.S. Ksenzhek, S.A. Petrova and M.V. Kolodyazhnyi, Sov. Electrochem., 20 (1984) 1385.

10 B. Ke, Arch. Biochem. Biophys., 68 (1957) 330.

11 Y. Asahi, J. Pharm. Soc. Jpn., 76 (1956) 378.

12 R.D. Draper and L.L. Ingraham, Arch. Biochem. Biophys., 125 (1968) 807.

13 L. Gorton and G. Johansson, J. Electroanal. Chem., 113 (1980) 151.

14 C.N. Durfor, B.A. Yenser and M.L. Bowers, J. Electroanal. Chem., 244 (1988) 287.

15 B.E. Conway, Electrochemical Data, Elsevier, Amsterdam, 1952, pp. 221-32.

16 V.I. Birss, H. Elzanowska and M.M. Kamal, J. Electroanal. Chem. (under review).

17 D. Krznaric, P. Valenta and H.W. Nurnberg, J. Electroanal. Chem., 65 (1975) 863.

18 P. Valenta and D. Krznaric, J. Electroanal. Chem., 75 (1977) 437.

19 G. Quarin, Electrochim. Acta, 29 (1984) 1707.

20 P. Valenta, H.W. Nurnberg and D. Krznaric, Bioelectrochem. Bioenerg., 3 (1976) 418.

21 V.I. Birss, D. Bizzotto, H. Elzanowska and M.M. Kamal, in preparation.

22 J. Christensen, J.H. Rytting and R.M. Izatt, Biochemistry, 9 (1970) 4907.

23 M.A. Jensen, T.E. Cummings and P.E. Elving, Bioelectrochem. Bioenerg., 4 (1977) 447.

24 M.M. Kamal, Ph.D. Thesis, Assiut University, Egypt.

25 Y.M. Temerk, M.M. Kamal, Z.A. Ahmed and M.S. Ibrahim, J. Electroanal. Chem., 260 (1989) 201.

26 D. Krznaric, P. Valenta, H.W. Nurnberg and M. Branica, J. Electroanal. Chem., 93 (1978) 41.

27 M. Temerk, P. Valenta and H.W. Nurnberg, Bioelectrochem. Bioenerg., 7 (1980) 705.

28 P. Valenta, H.W. Nurnberg and P. Klahre, Bioelectrochem. Bioenerg., 1 (1974) 487.

29 B. Malfoy, J.M. Sequaris, P. Valenta and H.W. Nurnberg, Bioelectrochem. Bioenerg., 3 (1976) 440.

30 P. Valenta, H.W. Nurnberg and P. Klahre, Bioelectrochem. Bioenerg., 2 (1975) 204.

31 H. Angerstein-Kozlowska, J. Klinger and B.E. Conway, J. Electroanal. Chem., 75 (1977) 45.

32 P. Hemmerich, C. Veeger and H.C.S. Wood, Angew. Chem. Int. Edn., 4 (1965) 671.

33 T.C. Bruice, Prog. Bioinorg. Chem., 4 (1976) 2.

34 S.W. Feldberg and I. Rubinstein, J. Electroanal. Chem., 240 (1988) 1.

35 R. Phillips, P. Eisenberg, P. George and R.J. Rutman, J. Biol. Chem., 240 (1965) 4393. 